\title{
The ugly, the bad and the good facets of COVID 19 in Nepal
}

\author{
Suman Baral ${ }^{1 *}$ (iD), Nuwdatta Subedi ${ }^{2}$ (D) \\ 'Department of Surgery, Dirghayu Pokhara Hospital, Pokhara, Nepal, ${ }^{2}$ Department of \\ Forensic Medicine, Gandaki Medical College Teaching Hospital, Pokhara Nepal
}

As expected, the second wave of the pandemic has hit really hard in the country and countrymen are striving for survival in the stretched health care system which was already disrupted during the first wave of the disaster. Various misbeliefs and misapprehension regarding health status and impregnable immunity of the Nepalese community, unchecked mass gatherings, social functions, and traditional values seem to have potentiated the upliftment of the dormant virus from the former disaster. ${ }^{1}$ The ugliest part of this scenario is that the health care has already been compromised, people are dying of unavailability of oxygen supply, ICU beds, ventilators, necessary medications like paracetamol and prednisolone, and above all, the worst scenario is that the sick are waiting their turn in emergencies and corridors for the vacancy of the beds when somebody gives up. ${ }^{2}$ Unaffordable treatment due to low financial economic status of the majority of the population, mortality surge among younger age groups, political turmoil despite of the ongoing disaster which needed utmost attention, mob mentality leading to vandalism against health care workers, and psycho-social issues associated with lockdown which has led to suicidal tendencies and suicidal deaths are the current hideous facets which need to be probed in no time. ${ }^{3,4}$

Once lockdown has been initiated, the main aim of this formula is to break the chain and disrupt the ecosystem of germs, however this golden opportunity of saving the world by the public just staying indoors and enjoying the Netflix movies and web series seems to be ignored. The impact of the COVID 19 pandemic on the daily wage group of the community may not be ignored, still, this should be addressed by the local government bodies for the facilitation of foods and necessary commodities. The current scenario has led to a late presentation to hospital for diseases other than COVID 19 including medical and surgical conditions, increase in the disease severity which created a detrimental impact on morbidity and mortality due to home-based remedies and treatment and thinking other differentials like typhoid for fever which created skepticism for getting treatment against COVID 19. Health care workers and front-liners became the scapegoat of the disease from the householders and were even asked to vacant the houses which potentiated the social stigma and reinforced the taboo of this disaster which have become somehow controlled in this long run from the first wave. ${ }^{5}$ Pay cuts in private-based institutions for doubling and tripling workloads and no supply of risk allowance to medicos created dissatisfaction among health care workers and seems to demoralize them for the work of humanity, though the scenario is indifferent.

The world seems to be halt, the ecology of the earth got rebooted, the environment got fumigated with fresh air and visibility seems to progress to infinity. We could see smiling clear vista of mountains and verdant hills, raw water streams in the rivers, blue lakes, and chirping of the passerines. The generous donations of medical sup- 
plies from developed countries to combat this disaster, facilitation in vaccination campaigns against COVID 19 which have almost covered a maximum number of health care workers which definitely impacts on fighting this dreadful enemy have created a silver lining of unmasked community with free mobility within and outside the physical borders. ${ }^{6}$ Innovations came up, ideas were generated, people started using masks, washing hands, and have been somewhat conscious about their own health perspective. The real fragility of the health system of the country has come into attention and hopefully, this will provide the opportunity for policymakers and stakeholders to act for the development of strong health care facilities within reach of more and more unprivileged ones. Hopefully, we will be adequately prepared for the third wave, and this too shall pass.

\section{REFERENCES}

1. Nepal's cases skyrocket, prompting concern the country's outbreak could mimic India's. Available from: https://edition.cnn.com/2021/05/06/asia/nepal-covid-outbreakintl-hnk-dst/index.html [Accessed 22nd May 2021].

2. Apparent rise in Covid-19 deaths in Nepal as second wave infections flare up. Available from: https://thehimalayantimes.com/nepal/apparent-rise-is-covid-19-deaths-innepal-as-second-wave-infections-flare-up [Accessed 22nd May 2021].

3. Nepal's silent epidemic of suicide during Covid-19 pandemic. Available from: https://english.onlinekhabar. com/nepals-silent-epidemic-of-suicide-during-covid-19pandemic.html [Accessed 22nd May 2021].

4. Health workers under attack as lack of Covid-19 awareness is fuelling stigma. Available from: https://kathmandupost.com/health/2020/08/23/health-workers-underattack-as-lack-of-covid-19-awareness-is-fuelling-stigma. [Accessed 22nd May 202].

5. Poudel K, Subedi P. Impact of COVID-19 pandemic on socioeconomic and mental health aspects in Nepal. Int J Soc Psychiatry. 2020;66(8):74855. DOI: $\quad 10.1177 / 0020764020942247$ PMID: 32650687.

6. Nepal among the first countries in Asia to receive COVID-19 vaccines from COVAX

Available from: https://www.unicef.org/nepal/press-releases/nepal-among-first-countries-asia-receive-covid19-vaccines-covax-facility [Accessed 22nd May 2021]. 